\title{
Leishmaniasis in Sri Lanka: spatial distribution and seasonal variations from 2009 to 2016
}

\author{
Lahiru Sandaruwan Galgamuwa ${ }^{1 *}$, Samath D. Dharmaratne ${ }^{2,3}$ and Devika Iddawela
}

\begin{abstract}
Background: Leishmaniasis is listed as one of the eight neglected tropical diseases by the World Health Organization and the number of cases in endemic areas has seen a sharp rise in the past decade. More alarmingly, reports have shown that leishmaniasis is spreading to non-endemic areas of the world due to co-infection with HIV. In Sri Lanka, leishmaniasis is considered as a notifiable disease from 2008 and has seen a rising trend of incidence since then. This is the first study describing the burden, seasonal variation and spatial distribution of leishmaniasis in Sri Lanka since the disease has been included as a notifiable disease.
\end{abstract}

Methods: Data on health statistics from 2009 to 2016 were obtained from published databases maintained by the Epidemiology Unit of the Ministry of Health in Sri Lanka. Climatic data for Sri Lanka were obtained from the Department of Meteorology and the populations in administrative districts were obtained from the Department of Census and Statistics, Sri Lanka. Descriptive spatiotemporal analysis, correlation between leishmaniasis incidence and climatic variables were analyzed using SPSS statistical software.

Results: The total number of people reported with leishmaniasis during the study period was 8487 . Cutaneous leishmaniasis is the prominent form in Sri Lanka while few visceral and muco-cutaneous cases were reported. Although leishmaniasis patients were identified from all 25 districts in the island, almost $90 \%$ of the total caseload was reported from Anuradhapura, Hambantota, Polonnaruwa, Kurunegala and Matara districts. The highest number of patients was reported from the Anuradhapura district and the highest incidence per 100,000 persons was reported from the Hambantota district. The disease has a seasonal trend, a peak of leishmaniasis occur in July to September in the north-central region and in October to December in the southern region. Maximum temperature, humidity and wind speed are significantly associated climatic variables with leishmaniasis in endemic regions.

Conclusions: Leishmaniasis is an emerging public health problem in north-central and southern Sri Lanka. Public awareness programs for the prevention and control of the disease in endemic regions are essential to reduce the incidence of leishmaniasis.

Keywords: Leishmaniasis, Spatial distribution, Seasonal variations

\footnotetext{
* Correspondence: lahiruahs@yahoo.com

${ }^{1}$ Department of Parasitology, Faculty of Medicine, University of Peradeniya,

Peradeniya, Sri Lanka

Full list of author information is available at the end of the article
} 


\section{Background}

Leishmaniasis is endemic in 88 countries, of which 66 are in the Old World, 22 in the New World and 72 of them are developing countries. It has been estimated that 350 million people are at risk of acquiring leishmaniasis, with approximately 0.2 to 0.4 million visceral leishmaniasis (VL) and 0.7 to 1.2 million cutaneous leismaniasis (CL) patients reporting in each year [1]. Changes of natural and man-made environments make leishmaniasis an emerging public health concern due to rapid urbanization, sharp increase in migration, deforestation and adaptation of the Leishmania parasite to additional vectors and mammalian hosts [2]. Furthermore, Leishmania has emerged as an opportunistic pathogen of HIV-infected adults as well as children [1]. The spectrum of clinical manifestations is large, ranging from the self-healing cutaneous lesions to the more serious, potentially fatal visceralizing form, including the metastasizing muco-cutaneous form, and the post kala-azar dermal leishmaniasis [3].

In Sri Lanka, during 1970s and 1980s, the disease was limited to a few cases among overseas employees returning to the country and remained sporadic in nature [4]. The first locally acquired CL infection was identified in 1992 from Southern Sri Lanka [5]. Since then the number of CL cases identified has increased dramatically. In addition, several sporadic locally acquired cases of mucocutaneous and visceral leishmaniasis have been reported in Sri Lanka [6]. Leishmania donovani zymodeme MON -37 was identified as the causative species responsible for CL in Sri Lanka [7]. DNA sequencing and microsatellite analyses have shown that these parasites are closely related to $L$. donovani MON-2 causing VL in the Indian subcontinent [8]. The same parasite, $L$. donovani of the zymodeme MON-37, also causes VL in India, Bangladesh and East Africa [9]. This dermotropism shown by L. donovani in Sri Lanka and in few other countries confirms the susceptibility of certain individuals to cutaneous form of leishmaniasis [10, 11]. Phlebotomus argentipes ( $P$. argentipes) is the main vector of L. donovani in Sri Lanka [7, 12]. Recent studies have identified all three members of the Phlebotomus argentipes species complex (P.glaucus, $P$. argentipes and $P$. annandalei) in northern Sri Lanka $[12,13]$. Distribution of the phlebotomine sand flies depends on geographical differences, abundance of vertebrate hosts, habitat availability and environmental factors such as rainfall and temperature [14, 15]. Hot and humid conditions have played an important role in the distribution of $P$. argentipes in Sri Lanka [4]. The disease has been made notifiable since 2008 and a national action plan has been developed in 2008 to control leishmaniasis [16]. According to recent research findings and records of the Ministry of Health, CL is now recognized as an endemic disease in the country.
Leishmaniasis has been reported mostly in low altitude areas of Sri Lanka. Although large number of published studies is available on the burden, risk factors and molecular characteristics of vectors and parasites, investigations on seasonality and spatial distribution of leishmaniasis are not adequately documented on Sri Lanka. The knowledge of geographical spread of leishmaniasis in Sri Lanka is still limited. Therefore, the present evaluation was conducted to identify the seasonal variation and spatial distribution of leishmaniasis in Sri Lanka using data available from 2009 to 2016. This analysis could be used to validate and assist the reconsideration of control strategies and national or regional policies for Sri Lanka and for other countries where leishmaniasis is endemic. In addition, this could provide information on the climatic factors that may potentially favor its spread and identify risk areas through comparison with data presented by other researchers in different geographical areas and used in future epidemiological studies, including those on climatic change. This study also provides information how climatic changes in tropical countries effect for the epidemiology of neglected diseases.

\section{Methods}

\section{Geography, population and climate}

Sri Lanka is a lower middle income country situated in the Indian Ocean with a long sea coast line between $5^{\circ} 55^{\prime}$ and $9^{\circ} 51^{\prime} \mathrm{N}, 79^{\circ} 42^{\prime}$ and $81^{\circ} 53^{\prime} \mathrm{E}$, to the Southeast of India. The total population of Sri Lanka is about 20.2 million living in an area covering $65,610 \mathrm{~km}^{2}$ in 2011 . Sri Lanka is divided into 9 provinces and 25 administrative districts (Fig. 1a). In Sri Lanka, 25\% of the population is under 14 years and $85 \%$ of population resides in rural areas [17]. The central part of the island is mountainous with mountains ranging in altitude between 500 and $2500 \mathrm{~m}$ and the remainder of the island consists of lowlands. The mean annual temperature of low altitudes (0-100 $\mathrm{m}$ above sea level) in Sri Lanka varies between 26.5-28.5 ${ }^{\circ} \mathrm{C}$ and the temperature decreases with increasing altitude. The mean annual temperature of NuwaraEliya district situated at the highest altitudes (1500$2500 \mathrm{~m}$ ) is $15.9^{\circ} \mathrm{C}$. Geographically, there are three climatic zones in Sri Lanka: western and southwestern areas form the wet zone; north-western and western slopes of the central mountain form the intermediate zone; and north, north-east, east and south-east areas form the dry zone (Fig. 1b).

In Sri Lanka, it was estimated that there was $26.6 \%$ of forest coverage in 2010 (Fig. 1c) [18]. Sri Lanka mainly consists of flat lands less than $300 \mathrm{~m}$ in elevation. However, rough plateau with hills and a range of moutains is in the south-central portion of Sri Lanka (Fig. 1d). Sri Lanka has a tropical climate and is affected by two major monsoons: From December to February, the north-east 


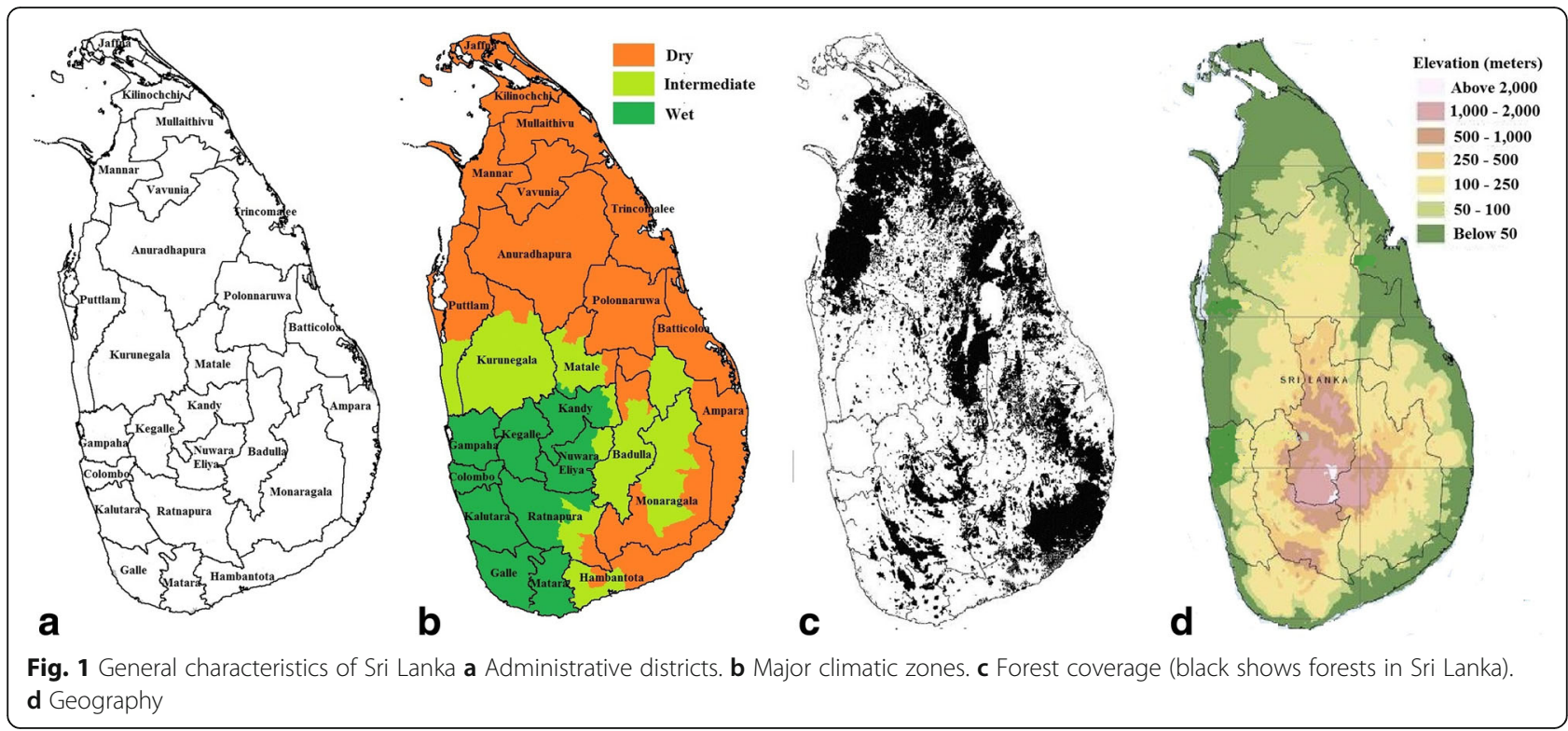

monsoon brings rain to the north, north-east regions and the eastern slopes of the central hill country and from June to October, the south-west monsoon brings rain to the south-west regions and central highlands [19]. April and August are the hottest months while January is the coolest month.

\section{Sampling of data \\ Leishmaniasis incidence data}

Morbidity related data were obtained from a published series of weekly reports, quarter year reports and annual health reports published by the Epidemiology Unit and Health Statistics Unit of the Ministry of Health, Sri Lanka for the period of 2009 to 2016. Leishmaniasis was made a notifiable disease in Sri Lanka in 2008, and therefore, reporting of all persons with leishmaniasis to the relevant Medical Officer of Health $(\mathrm{MOH})$ is a legal requirement.

\section{Climatic and population data}

Data (monthly) on temperature, rainfall, humidity, wind speed, cloud, sunny days and sun hours in Sri Lanka during the study period (2009-2016) were collected from the Department of Meteorology, Sri Lanka. The populations in administrative districts were ascertained from the Department of Census and Statistics, Sri Lanka for the study period.

\section{Data analysis}

Reported cases of leishmaniasis were gathered from established worksheets and calculated cases for annual level and quarters of the year in the district level. Total human populations in the administrative districts were taken to calculate the leishmaniasis incidence per
100,000 people for 8 years from 2009 to 2016. Twelve months have been divided into four quarters as Quarter 1 (January, February, March), Quarter 2 (April, May, June), Quarter 3 (July, August, September) and Quarter 4 (October, November, December) to describe the seasonal fluctuations of disease incidences. Time series informations including number of leishmaniasis patients, trend and seasonal variations and seasonal adjusted leishmaniasis patients were analysed in each endemic districts from 2009 to 2016.

Data were entered into a Microsoft Excel data sheet and was analyzed by SPSS version 20 for statistical analysis. Descriptive statistics were calculated including percentage, mean and standard deviation to describe the univariate analysis. Pearson's correlation coefficient analysis was applied to determine the association between climatic parameters and leishmaniasis incidence in endemic districts. Multiple regression method was used to determine the predictive effect of the climatic factors on the incidence of leishmaniasis. A 95\% confidence level was used and $P$-value less than 0.05 was considered statistically significant.

Auto Regressive Integrated Moving Average (ARIMA) model was used to model and predict the incidence of leishmaniasis. Autocorrelation functions were used to to identify autoregressive functions. In time series analysis, the extent of the lag in an autoregressive model was identified by the partial autocorrelation function (PACF) for seasonal data.

\section{Results}

\section{Spatial distribution of leishmaniasis}

The total number of diagnosed leishmaniasis patients reported from 2009 to 2016 was 8487. Since 2012, more than 1000 cases have been newly identified annually and the 
Table 1 Distribution of leishmaniasis cases in each district from 2009 to 2016

\begin{tabular}{|c|c|c|c|c|c|c|c|c|}
\hline District & 2009 & 2010 & 2011 & 2012 & 2013 & 2014 & 2015 & 2016 \\
\hline Colombo & 2 & 3 & 1 & 4 & 1 & 3 & 1 & 0 \\
\hline Gampaha & 2 & 3 & 0 & 1 & 5 & 3 & 3 & 7 \\
\hline Kalutara & 1 & 1 & 1 & 3 & 0 & 0 & 0 & 0 \\
\hline Kandy & 0 & 0 & 2 & 0 & 6 & 5 & 17 & 13 \\
\hline Matale & 14 & 3 & 16 & 46 & 20 & 32 & 36 & 26 \\
\hline Nuwara Eliya & 2 & 1 & 0 & 0 & 0 & 0 & 2 & 0 \\
\hline Galle & 1 & 0 & 1 & 1 & 2 & 3 & 3 & 3 \\
\hline Hambantota & 262 & 139 & 268 & 335 & 371 & 375 & 325 & 390 \\
\hline Matara & 95 & 25 & 57 & 92 & 107 & 94 & 166 & 197 \\
\hline Jaffna & 0 & 0 & 0 & 0 & 0 & 1 & 0 & 1 \\
\hline Kilinochchi & 0 & 0 & 0 & 4 & 13 & 11 & 0 & 0 \\
\hline Mannar & 0 & 0 & 0 & 4 & 4 & 5 & 1 & 0 \\
\hline Vavuniya & 1 & 1 & 0 & 10 & 17 & 6 & 9 & 8 \\
\hline Mullaitivu & 1 & 0 & 0 & 9 & 19 & 7 & 9 & 6 \\
\hline Batticaloa & 0 & 0 & 0 & 2 & 0 & 0 & 0 & 1 \\
\hline Ampara & 2 & 3 & 3 & 2 & 4 & 12 & 3 & 9 \\
\hline Trincomalee & 12 & 11 & 9 & 17 & 30 & 9 & 6 & 18 \\
\hline Kurunegala & 6 & 25 & 46 & 56 & 63 & 152 & 150 & 111 \\
\hline Puttalam & 1 & 1 & 2 & 3 & 13 & 9 & 3 & 4 \\
\hline Anuradhapura & 226 & 169 & 358 & 434 & 443 & 417 & 347 & 276 \\
\hline Polonnaruwa & 34 & 26 & 156 & 143 & 178 & 153 & 130 & 136 \\
\hline Badulla & 3 & 0 & 0 & 0 & 9 & 1 & 8 & 4 \\
\hline Monaragala & 0 & 4 & 2 & 14 & 15 & 33 & 40 & 40 \\
\hline Ratnapura & 11 & 8 & 18 & 35 & 18 & 34 & 19 & 1 \\
\hline Kegalle & 0 & 3 & 0 & 2 & 2 & 2 & 0 & 3 \\
\hline Total & 674 & 428 & 940 & 1219 & 1342 & 1367 & 1277 & 1240 \\
\hline
\end{tabular}

Sources: Epidemiological data, Ministry of Health, Sri Lanka

highest number recorded in 2014 (Table 1). At the beginning of the study period, the disease was mainly concentrated in a few districts (Anuradhapura, Hambantota, Polonnaruwa and Matara) and with time, it spread to other districts (Fig. 2). Although leishmaniasis have been reported from all districts, Anuradhapura, Hambantota, Polonnaruwa, Kurunegala and Matara were the districts identified with more than 100 new patients annually. During the period of 2009-2016, the highest number of leishmaniasis patients was reported in the Anuradhapura district (2671) and it was 31.5\% of all identified patients in this period. The second highest number of patients were identified in the Hambantota district (2465; $29 \%$ ) followed by Polonnaruwa district (956; 11.3\%), Matara district (833; 9.8\%) and Kurunegala district (609; 7.2\%). These five districts contributed around $90 \%$ of patients with leishmaniasis (7534, 88.8\%) (Fig. 2). Out of these districts from 2009 to 2016, an 18.5-fold increase in Leishmania patients was shown in Kurunegala district followed by a 4-fold

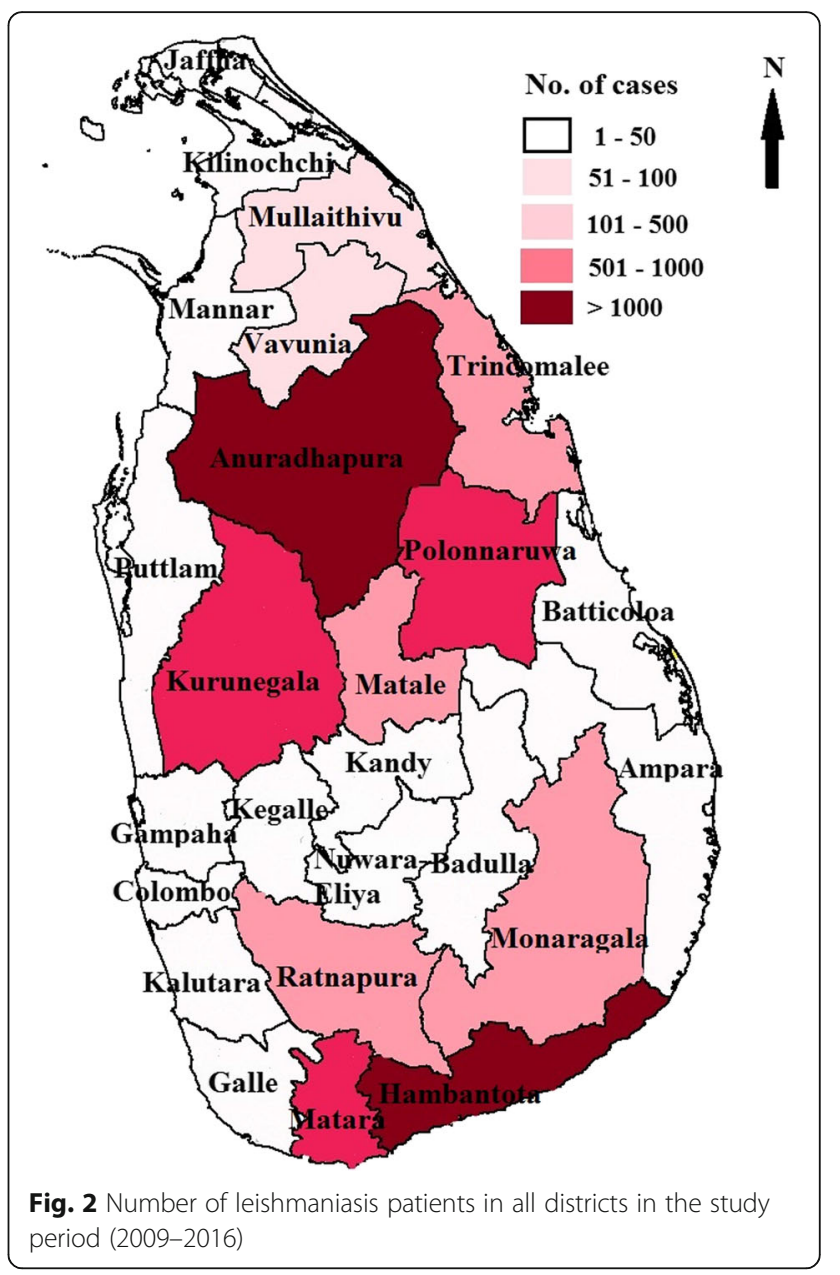

increase in the Polonnaruwa, and a 2.1-fold increase in Matara district. In addition, the number of leishmaniasis patients increased 10-fold in the Monaragala district (2010: 4 patients, 2016: 40 patients).

Furthermore, the incidence of leishmaniasis patients per 100,000 people in Anuradhapura, Polonnaruwa and Hambantota districts rapidly increased during the period of 2010 to 2012. In addition, a rapid increase of patients was observed in Matara district from 2014 to 2016 (Table 1) and further to this, the notified cases of identified Leishmania patients gradually increased in Matale, Trincomalee and Mullaithivu districts. However, very low numbers of patients were identified in the western province (Colombo, Gampaha and Kalutara districts), Central highlands (Kandy, Nuwara-Eliya, Badulla and Kegalle districts) and the Jaffna Peninsula (Table 1).

When considering the incidence rate of leishmaniasis, more than 30 patients per 100,000 people were identified in Hambantota district in 2010. However in 2016, Hambantota (45.3), Anuradhapura (30.7), Polonnaruwa (32) and Matara (30.3) districts showed an incident rate of more than 30. In addition, the rate of leishmaniasis 
incidence in Kurunegala, Matale, Monaragala and Mullaithivu districts has become more than 5 per 100,000 people (Fig. 3).

\section{Seasonality and distribution of $\mathrm{CL}$}

The top panel of Fig. 4 shows the distribution of the quartery cases of the disease cases of leishmaniasis in Sri Lanka between 2009 and 2016. The second panel is the trend component, which indicates a steady increase in leishmaniasis cases in Anuradhapura, Polonnaruwa and Hambantota districts from 2010 to 2012. Meanwhile, a sharp increasement of leishmaniasis cases in Matara and Kurunegala districts showed from 2014 to 2016. However, a decreasing trend of leishmaniasis cases showed in Anuradhapura district after 2012. The leishmaniasis incidence in Sri Lanka shows a seasonal trend, a peak in July to September, between the two monsoon periods. Meanwhile, during March-June there was a drop in the number of reported cased compared to the rest of the months. The third panel is the seasonal component, which shows the highest incidence rate in Anuradhapura district was reported during the third quarter (July-September). However, highest number of leishmaniasis patients in Polonnaruwa and Hambantota districts was reported in the fourth quarter (October-December). In addition, a similar number of new cases was identified in Matara district throughout the year since it is situated in wet zone. Meanwhile decreasing trends of leishmaniasis showed in north-central regions (Anuradhapura and Polonnaruwa districts) and increasing trends showed in north-western and southern regions (Hambantota, Matara and Kurunegala districts, Fig. 4).

\section{Correlation between climatic parameters and leishmaniasis cases}

Correlation coefficients between the incidence of leishmaniasis and climate parameters were analyzed. Significantly positive correlations with monthly average and maximum temperatures were observed with the incidence of leishmaniasis in Hambantota and Matara districts. In addition, a significant negative correlation between leishmaniasis cases and humidity was observed in Matara district. Furthermore, wind speed and wind gust is positively correlated in Anuradhapura district. There was no correlation between leishmaniasis case incidence and any of the analyzed climatic parameters in Polonnaruwa and Kurunegala districts. In addition, negative correlations were observed between monthly average rainfall and leishmaniasis in Anuradhapura, Polonnaruwa, Hambantota and Matara districts (Table 2).

\section{Modeling and prediction of leishmaniasis incidence and climatic factors}

Multiple regression analysis and autoregression analysis were used to identify a model and predictors associated with the incidence of leishmaniasis in endemic districts. Average wind speed was identified as a predictor in Polonnaruwa district. Meanwhile, humidity and maximum temperature were associated in Hambantota district. In addition, sun-hours were significantly associated in both ambantota and Kurunegala districts. However, no climatic factors were significantly found to be correlated with the incidence of leismaniasis in Anuradhapura and Matara districts (Table 3).

An ARIMA model was used to analyze autoregression of seasonal data. The autocorrelation plots show a significant autocorrelation at lag 1 in all endemic districts. Further, partial autocorrelation function (PACF) shows from seasonal data insignificant spikes at the mentioned lags in Anuradhapura (9th lag) and Hambantota (4th lag) concluding no evidence of non-randomness process (Fig. 5). In addition, Polonnaruwa, Matara and Kurunegala districts had only one large significant spike at lag 1 , which

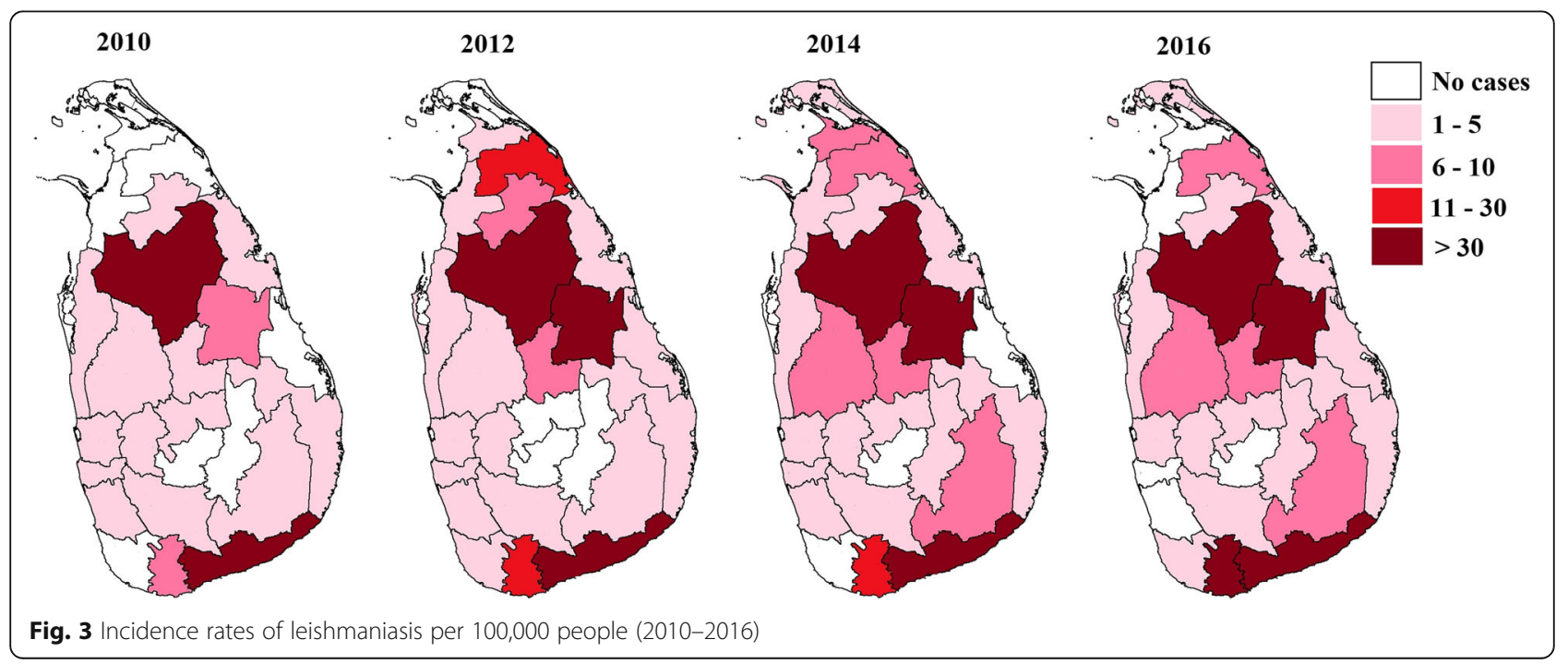




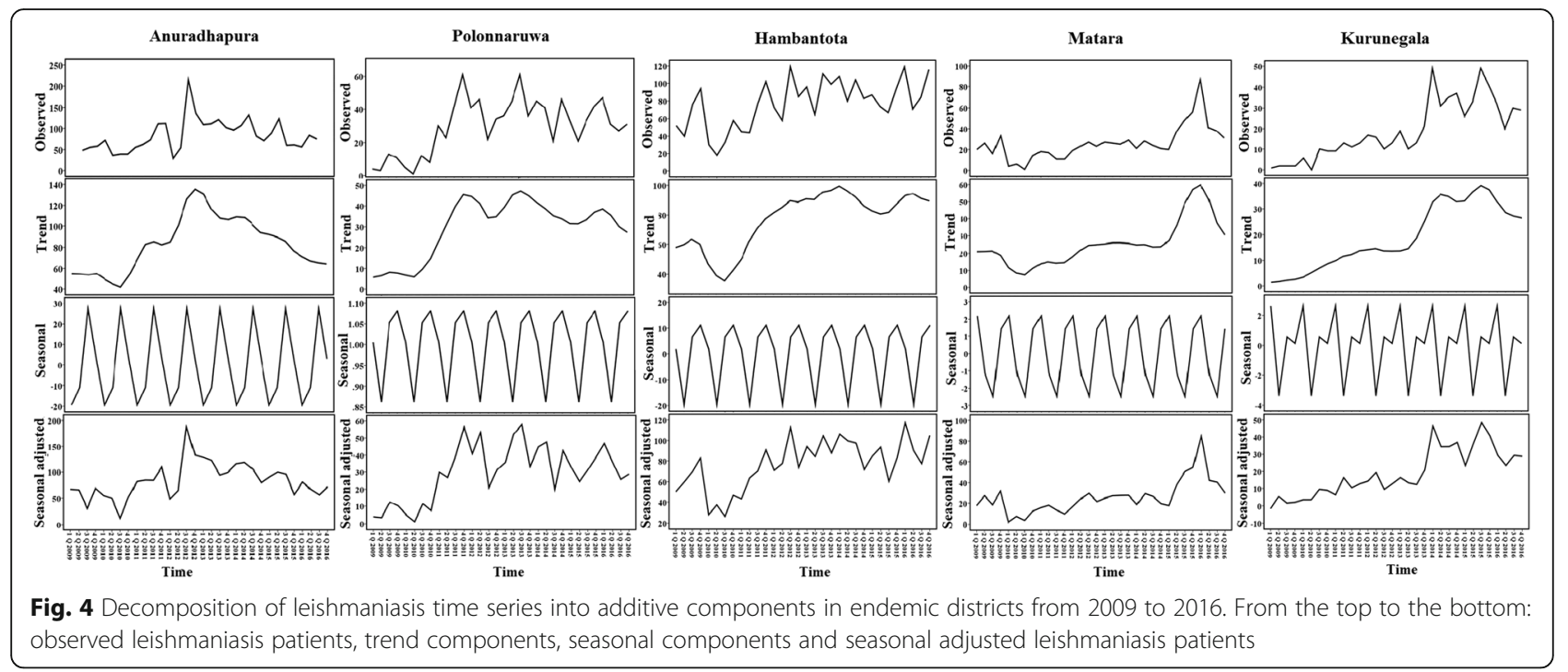

implies that we can discard the longer lags for those districts (Fig. 5).

\section{Discussion}

Morbidity data are important for planning and evaluation of the health care system in a country. Sri Lanka is endemic for leishmaniasis caused by Leishmania donovani. For several decades, the public health awareness of the leishmaniasis and its impact on health was underestimated. To our knowledge, this is the first study in Sri Lanka to investigate the spatial distribution of leishmaniasis after it has been declared as a notifiable disease from 2008. At the beginning, the disease was mainly concentrated in a few districts, namely Anuradhapura, Polonnaruwa and Hambantota. Over the last decade, it spread out to other districts and number of recorded cases has sharply increased in Sri Lanka.

Although leishmaniasis has been reported from all districts, Anuradhapura, Hambantota, Polonnaruwa, Kurunegala, and Matara were the districts identified with more than 100 new patients annually. Out of them Anuradhapura, Polonnaruwa and Hambatota are situated in the dry zone while Kurunegala and Matara districts are located in the intermediate and wet zones, respectively. These results showed that there is an emerging epidemic of leishmaniasis in the southern, north-western and north-central regions of the island. The highest incidence was recorded in the Anuradhapura and Hambantota districts indicating an endemic hot spot affecting the provinces of north-central and southern Sri Lanka as its epicenter. These areas may be serving as source for

Table 2 Correlation between lesihmaniasis and monthly average climatic parameters in endemic districts

\begin{tabular}{|c|c|c|c|c|c|c|c|c|c|c|}
\hline \multirow[t]{2}{*}{ Climatic parameters } & \multicolumn{2}{|c|}{ Anuradhapura } & \multicolumn{2}{|c|}{ Polonnaruwa } & \multicolumn{2}{|c|}{ Hambantota } & \multicolumn{2}{|l|}{ Matara } & \multicolumn{2}{|c|}{ Kurunegala } \\
\hline & $r$ & $P$-value & $r$ & $P$-value & $r$ & $P$-value & $r$ & $P$-value & $r$ & $P$-value \\
\hline Minimum temperature & 0.326 & 0.090 & -0.114 & 0.564 & 0.214 & 0.274 & 0.251 & 0.197 & -0.307 & 0.112 \\
\hline Maximum temperature & 0.025 & 0.898 & -0.074 & 0.714 & 0.494 & 0.008 & 0.591 & 0.001 & 0.357 & 0.062 \\
\hline Average temperature & -0.174 & 0.174 & -0.063 & 0.751 & 0.417 & 0.027 & 0.684 & $<0.001$ & 0.173 & 0.378 \\
\hline Rainy days & -0.315 & 0.103 & -0.082 & 0.678 & -0.109 & 0.579 & -0.121 & 0.540 & 0.113 & 0.566 \\
\hline Rainfall & -0.272 & 0.161 & -0.163 & 0.407 & -0.042 & 0.833 & -0.418 & 0.027 & 0.106 & 0.591 \\
\hline Average wind speed (mph) & 0.516 & 0.005 & 0.036 & 0.854 & 0.186 & 0.344 & 0.307 & 0.112 & 0.133 & 0.501 \\
\hline Maximum wind speed (mph) & 0.596 & 0.002 & 0.061 & 0.607 & 0.359 & 0.060 & 0.134 & 0.498 & 0.185 & 0.345 \\
\hline Average wind gust (mph) & 0.569 & 0.002 & 0.102 & 0.757 & 0.197 & 0.314 & 0.088 & 0.655 & 0.114 & 0.564 \\
\hline Humidity & -0.358 & 0.061 & 0.012 & 0.607 & -0.033 & 0.869 & -0.584 & 0.001 & 0.008 & 0.966 \\
\hline Cloud (\%) & 0.041 & 0.837 & 0.073 & 0.713 & -0.253 & 0.194 & -0.055 & 0.780 & 0.070 & 0.723 \\
\hline Sunny days & 0.176 & 0.371 & 0.095 & 0.631 & 0.212 & 0.278 & 0.138 & 0.485 & 0.048 & 0.807 \\
\hline Sun hours & 0.191 & 0.331 & -0.143 & 0.469 & -0.297 & 0.330 & -0.086 & 0.660 & -0.165 & 0.403 \\
\hline
\end{tabular}


Table 3 Multiple regression method to model leishmaniasis cases using climatic variables

\begin{tabular}{|c|c|c|c|c|c|c|c|c|c|c|}
\hline \multirow[b]{2}{*}{ Climatic variables } & \multicolumn{2}{|c|}{ Anuradhapura } & \multicolumn{2}{|c|}{ Polonnaruwa } & \multicolumn{2}{|l|}{ Hambantota } & \multicolumn{2}{|l|}{ Matara } & \multicolumn{2}{|l|}{ Kurunegala } \\
\hline & $\begin{array}{l}\text { Coefficient } \\
\text { of variable }\end{array}$ & $P$-value & $\begin{array}{l}\text { Coefficient } \\
\text { of variable }\end{array}$ & $P$-value & $\begin{array}{l}\text { Coefficient } \\
\text { of variable }\end{array}$ & $P$-value & $\begin{array}{l}\text { Coefficient of } \\
\text { variable }\end{array}$ & $P$-value & $\begin{array}{l}\text { Coefficient of } \\
\text { variable }\end{array}$ & $P$-value \\
\hline Constant & 509.05 & 0.146 & -478.52 & 0.493 & -327.84 & 0.001 & -567.43 & 0.960 & -485.88 & 0.055 \\
\hline R-square & 0.587 & & 0.444 & & 0.833 & & 0.620 & & 0.658 & \\
\hline Minimum temperature & -9.79 & 0.545 & 8.92 & 0.326 & -0.02 & 0.742 & 2.95 & 0.760 & 0.01 & 0.903 \\
\hline Maximum temperature & 25.37 & 0.376 & -2.90 & 0.686 & 20.70 & 0.036 & 7.92 & 0.480 & 1.41 & 0.793 \\
\hline Average temperature & -21.95 & 0.302 & 3.76 & 0.676 & -11.82 & 0.167 & 0.35 & 0.960 & 6.95 & 0.071 \\
\hline Rainy days & -3.78 & 0.533 & 1.12 & 0.699 & 5.58 & 0.084 & 6.76 & 0.110 & 0.67 & 0.640 \\
\hline Rainfall & -0.04 & 0.889 & -0.13 & 0.313 & -0.11 & 0.460 & -0.15 & 0.180 & 0.00 & 0.911 \\
\hline Average wind speed & -4.53 & 0.543 & -38.87 & 0.044 & -4.26 & 0.794 & 2.70 & 0.260 & 3.44 & 0.565 \\
\hline Maximum wind speed & 28.97 & 0.159 & 22.43 & 0.054 & 7.81 & 0.040 & -3.17 & 0.780 & -1.67 & 0.799 \\
\hline Average wind gust & -14.94 & 0.454 & 11.29 & 0.285 & 8.42 & 0.467 & 5.46 & 0.570 & 4.19 & 0.289 \\
\hline Humidity & -2.03 & 0.775 & 3.09 & 0.340 & -3.04 & 0.019 & 2.08 & 0.610 & -1.43 & 0.087 \\
\hline Cloud & -0.32 & 0.840 & -0.45 & 0.701 & 2.33 & 0.593 & -2.00 & 0.380 & 4.09 & 0.108 \\
\hline Sunny days & -6.76 & 0.288 & 0.04 & 0.989 & 0.70 & 0.802 & 4.96 & 0.270 & 0.96 & 0.467 \\
\hline Sun hours & -0.49 & 0.507 & -0.30 & 0.582 & -1.67 & 0.003 & -0.18 & 0.770 & -0.75 & 0.017 \\
\hline
\end{tabular}

leishmaniasis transmission from which the disease can spread to adjoining areas as well. Previous studies reported that the risk factors for leishmaniasis in endemic areas in Sri Lanka associated with the life style of the young male adults aged between 21 and 40 years having outdoor activities during the daytime [7, 16, 20]. People in this age group are most active due to their high level of social activity, occupation and education, thus the risk of exposure to sand fly bites is high. The distribution of leishmaniasis cases throughout the dry zone is unlike that of a recently introduced disease.
In addition to main endemic districts, the number of leishmaniasis cases reported in Matale, Ratnapura, Trincomalee, Mullaithvu and Monaragala districts has seen a gradual increase from 2009 to 2016. All of these are neighboring districts and the climatic and socio demographic characteristics are similar to that of major endemic districts. Movements of leishmaniasis patients and rervoir hosts from high risk areas to non-endemic areas may be the main factor for this finding.

Sand flies are most active from dusk to dawn. However, they are less active during the hottest times of

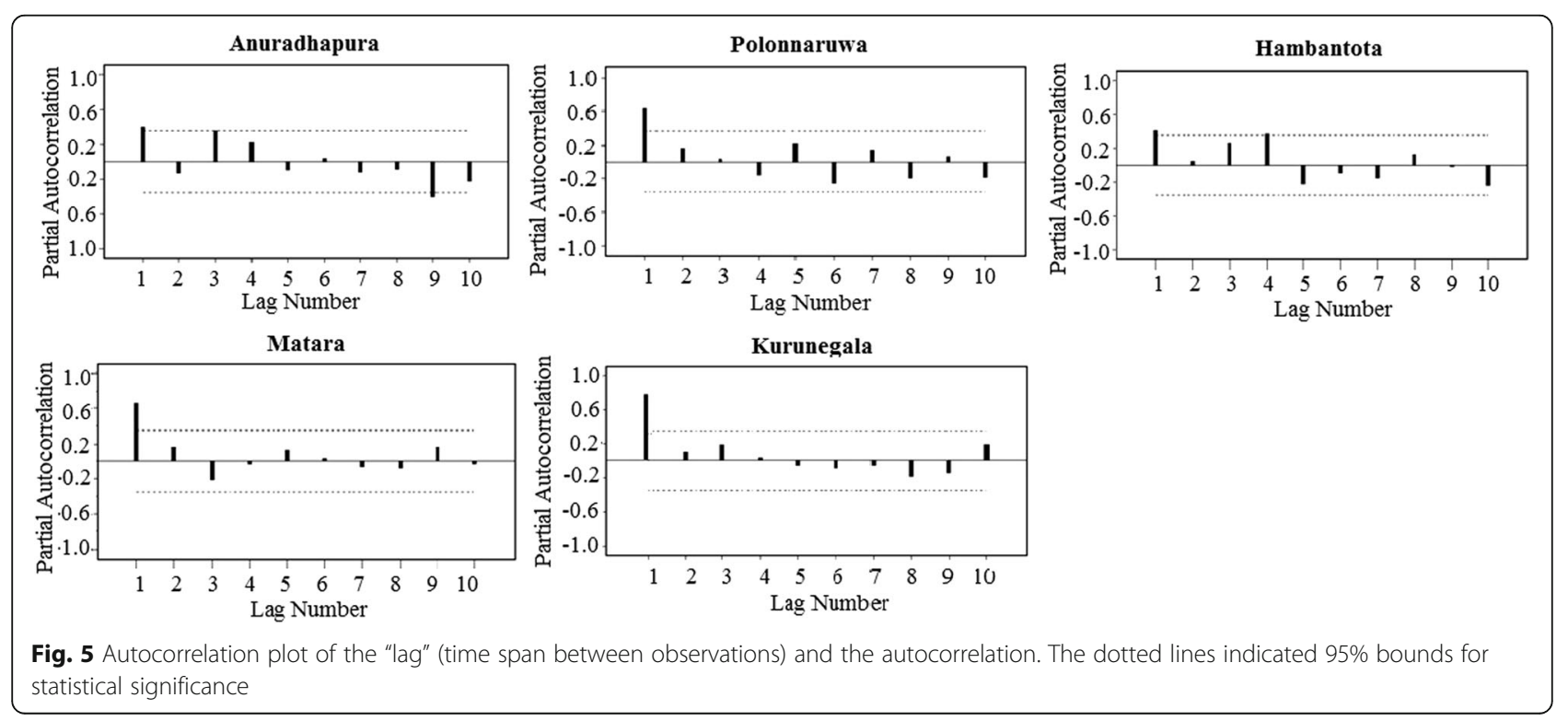


the day. The female sand fly lays eggs in the bark and buttress roots of old trees, in ruined buildings, in cracks in house walls, in animal shelters and in household rubbish termite mounds and animal burrows having rich humus and moisture [21, 22]. These microhabitats provide shelter and breeding sites for sand flies and protect them from climatic changes such as sunlight, rain and wind. Populations of sand flies are generally localized and therefore individuals do not disperse far from their breeding sites [23]. Therefore, their breeding and resting places exist very close proximity to human settlements [24].

Agriculture related activities are the main livelihood of the inhabitants of these endemic areas. People in the dry and the intermediate climatic zones in Sri Lanka are mainly paddy farmers and are involved with chena cultivation during day time. The agricultural activity facilitates favorable resting and breeding habitats for sand flies, thus increasing the risk of infection [25]. Large scale irrigation systems throughout the endemic districts enhance the moisture rich soil and provide vector breeding places in agriculture lands [26]. Therefore, the abundance of sand fly population and breeding places can be found in agricultural lands close to human settlements, increasing the risk of disease. Previous studies have reported that most of leishmaniasis patients work in open environments such as agricultural farms and fields wearing clothes to cover only lower part of the body. Therefore, the exposure of sand fly bites to upper part of the body was higher compare to lower parts [27]. In addition, persons working in the armed forces have been identified as a high risk group to leishmaniasis [28]. The reason for its spread has been associated with the movement of military personnel into former uninhabited areas in north and north-central provinces due to the civil war [29].

Studies conducted in the southern region (Hambantota and Matara) reported that household clustering and poor housing conditions were associated with leishmaniasis, favoring a peridomestic transmission $[8,30]$. Poverty plays a major role in facilitating poor sanitary and housing conditions which contribute to enhancing peridomestic sand fly breeding and resting sites [31]. More than $80 \%$ of houses in the rural sector in Sri Lanka still use firewood for cooking while only one third of urban households use wood [17]. Therefore, a majority of rural women often go to forests and scrub jungles to collect firewood. They therefore have a risk of exposure to sand fly bites because of the abundance of sand fly breeding sites present in rural areas. Geographically, the majority of scrub jungles and forests present in north, north-central, north-western and southeastern areas are the regions where leishmaniasis is endemic. Frequent visits and activities related to scrub jungle have been identified as a risk factor for Leishmania infection [28]. Most leishmaniasis is zoonotic and humans become infected only when accidentally exposed to the transmitting sand flies.

Previous studies reported that the occurrence of leishmaniasis is seasonal [32-34]. Climatic changes in rainfall, humidity and atmospheric temperature influence behavioral activities and the life-cycle of vectors and reservoir hosts for leishmaniasis $[35,36]$. A study in India reported that $29{ }^{\circ} \mathrm{C}$ to $31{ }^{\circ} \mathrm{C}$ was the most favorable range of the distribution of leishmaniasis, suggesting the potential of $P$. argentipes abundance in higher temperatures [37]. In the present study, we identified that all of the endemic regions are situated in low altitude areas less than $100 \mathrm{~m}$ above sea level and the mean temperature of all of these districts range between 26.5$28.5^{\circ} \mathrm{C}$. In Matara and Hambantota districts in the southern province, we observed a positive correlation between leishmaniasis and the mean and minimum average temperatures. In addition, the correlation between all other climatic parameters with the incidence of leishmaniasis was similar in Matara and Hambantota districts. This may be due to both of these districts being neighboring districts and having similar climatic characteristics. Similarly, a study in Bangladesh observed that a high incidence of the disease occurred during the warm months [22].

A previous study reported that $P$. argentipes is present at almost all altitudes in Sri Lanka [38]. However, this study shows that the highest incidence of leishmania patients was found less than $100 \mathrm{~m}$ above sea level. Another study identified the highest density of $P$. argentipes in the southern province where leishmaniasis is an emerging epidemic disease [39]. In addition, a recent study in Iran showed that optimal atmospheric conditions for breeding and maturation of sand fly vectors are present in low altitude areas [40]. In the present study, we identified that the incidence of leishmaniasis at high altitudes is very low compared to the cases identified from areas situated in low altitudes. Temperature gradually decreases with an increase in altitude. Sand fly prefer to live in environments with high humidity of $70-100 \%$ and rainfall helps to increase relative humidity $[41,42]$. With increasing altitude, the air gets cooler resulting in low humidity at high altitudes. Therefore, the environmental conditions in mountainous regions are unfavorable for the breeding and maturation of sand flies. In addition, lesser human activity on the environment at high altitudes minimizes the exposure of sand fly bites at high altitudes [38]. Similarly, studies in India and Turkey reported that the abundance of sand flies showed a negative correlation with an increase in altitude [43, 44]. Another study in India identified that the number of kala-azar cases decreased with an increase in altitude and no kala-azar case was recorded beyond the $300 \mathrm{~m}$ in altitude, suggesting that altitudes play a major role in the distribution of the sand fly [24]. 
In the present study, a greater number of leishmaniasis cases were reported in dry seasons (July-September). This was consistent with studies in Colombia and Ethiopia, which reported that the increased frequency of droughts is likely to increase the incidence of the disease $[45,46]$. In dry conditions like droughts, people in rural areas cluster around water supplies because of the limited water sources, exposing them to a high concentration of vector populations. Bhunia et al. [24] reported that there was a strong association between visceral leishmaniasis and water bodies and showed a decreasing trend of the disease with increased distance from water bodies in India. Other studies in India and Bangladesh reported that the incidence of leishmaniasis of flood controlled areas was significantly higher than flooding areas, suggesting that flooding removes organic matters and vector breeding sites $[47,48]$. Interestingly, this fact is negatively correlated with increased rainfall in endemic regions. One of the possible reasons for this relation is that high humidity in dry seasons contributes breeding and dissemination of sand fly vectors [48]. In addition, increasing movements of humans in cultivated and forest areas during dry seasons might contribute to an increase in the exposure to sand fly bites.

Finally, we suggest that the transmission of leishmaniasis is linked by human behavior of outdoor activities under climatic conditions favoring the maturation and distribution of sand flies. Future studies of bionomics on vector, parasite and reservoir hosts, morphological variations of the infection will be important to understand the epidemiology of leishmaniasis in Sri Lanka. There were several limitations in this study. The present reporting and recording of data as a total count per district may not reflect the actual case burden. In some instances the persons with the disease were limited only to certain clusters. In addition, the true correlations cannot be calculated due to the following reasons: patient records represent as total for the whole district (No GNDs or $\mathrm{MOH}$ ) and climatic data represent only one station. Significant variations in different micro-climate and micro-level habitats that may be present in individual districts could not be included in this analysis. Therefore, this analysis may misinterpret the actual epidemiology of the disease. We hope to discuss these issues with the Ministry of Health and provincial ministries of health to review and improve the data collection systems for this important public health problem.

\section{Conclusions}

Leishmaniasis is endemic in north-central, north-western and southern regions of Sri Lanka. People living at low altitudes and close to paddy fields and forests have a high risk of acquiring the disease. Temperature, humidity and wind speed contribute to transmission of leishmaniasis in endemic regions. In addition, there is a negative correlation between rainfall and leishmaniasis in Matara district. Health education of the disease, both for public and health workers, identifying reservoir hosts and vector control will be important initiatives to prevent the spread of this disease in Sri Lanka.

\section{Abbreviations \\ CL: Cutaneous leishmaniasis; DHS: Demographic and health survey; VL: Viceral leishmaniasis; WHO: World Health Organization}

\section{Acknowledgements}

We would like to express our deepest gratitude to the academic and nonacademic staff of the Department of Parasitology, Faculty of Medicine, University of Peradeniya.

\section{Funding}

This research received no specific grant from any funding agency in the public, commercial or not-for-profit sectors.

\section{Availability of data and materials}

All data generated or analyzed during this study are not publicly available due to maintaining the privacy of the individuals' identities. The dataset supporting the conclusions is available upon request to the corresponding author.

\section{Authors' contributions}

SD and LSG conceived and designed the study. LSG and SD were involved to data interpretation and statistical analysis. LSG wrote the first draft of the manuscript. DI and SD critically revised the manuscript for intellectual content. All authors read and approved the final manuscript.

\section{Ethics approval and consent to participate}

The ethical clearance was approved by the ethics review committee, Faculty of Medicine, University of Peradeniya, Sri Lanka. This is a retrospective study and the permission to review data was obtained from administrative and health authorities.

\section{Consent for publication}

Not applicable.

\section{Competing interests}

The authors declare that they have no competing interests.

\section{Publisher's Note}

Springer Nature remains neutral with regard to jurisdictional claims in published maps and institutional affiliations.

\section{Author details}

${ }^{1}$ Department of Parasitology, Faculty of Medicine, University of Peradeniya, Peradeniya, Sri Lanka. ${ }^{2}$ Department of Community Medicine, Faculty of Medicine, University of Peradeniya, Peradeniya, Sri Lanka. ${ }^{3}$ Institute for Health Metrics and Evaluation, Department of Global Health, School of Public Health, University of Washington, Seattle, USA.

Received: 2 August 2017 Accepted: 15 January 2018

Published online: 25 January 2018

References

1. Alvar J, Velez ID, Bern C, Herrero M, Desjeux P, Cano J, et al. Leishmaniasis worldwide and global estimates of its incidence. PLoS One. 2012;7:e35671

2. Ferro C, Marín D, Góngora R, Carrasquilla MC, Trujillo JE, Rueda NK, et al. Phlebotomine vector ecology in the domestic transmission of American cutaneous leishmaniasis in Chaparral, Colombia. Am J Trop Med Hyg. 2011;85:847-56.

3. Teixeira MJ, Fernandes JD, Teixeira CR, Andrade BB, Pompeu ML, Silva JS, et al. Distinct Leishmania braziliensis isolates induce different paces of chemokine expression patterns. Infect Immunol. 2005;73:1191-5. 
4. Lane RP, Pile MM, Amerasinghe FP. Anthropophagy and aggregation behavior of the sandfly Phlebotomies argentipes in Sri Lanka. Med Vet Entomol. 1990;4:79-88.

5. Athukorale DN, Seneviratne JK, Ihalamulla RL, Premaratne UN. Locally acquired leishmaniasis in Sri Lanka. J Trop Med Hyg. 1992;95:432-3.

6. Abeygunasekara PHY, Costa J, Seneviratne N, Ratnatunga N, Wijesundera SM. Locally acquired visceral leishmaniasis in Sri Lanka. Ceylon Med J. 2007;52:30-1.

7. Karunaweera ND, Pratlong F, Siriwardane HV, Ihalamulla RL, Dedet JP. Sri Lankan cutaneous leishmaniasis is caused by Leishmania donovani zymodeme MON-37. Trans R Soc Trop Med Hyg. 2003;97:1-2.

8. HVYD S, Noyes HA, Beeching NJ, Chance ML, Karunaweera ND, Bates PA Leishmania donovani and cutaneous leishmaniasis in Sri Lanka. J Emerg Infect Dis. 2007;13:476-8.

9. Davies CR, Kaye P, Croft SL, Sundhar S. Leishmaniasis: new approaches to disease control. BMJ. 2003:326:377-82

10. Elamin EM, Guizani I, Guerbouj S, Gramiccia M, El Hassan AM, Di Muccio T, et al. Identification of Leishmania donovani as a cause of cutaneous leishmaniasis in Sudan. Trans Soc Trop Med Hygiene. 2008;102:54-7.

11. Samaranayake TN, Dissanayake VH, Fernando SD. Clinical manifestations of cutaneous leishmaniasis in Sri Lanka - possible evidence for genetic susceptibility among the Sinhalese. Ann Trop Med Parasitol. 2008;102:383-90.

12. Surendran SN, Karunaratne SH, Adams Z, Hemingway J, Hawkes NJ. Molecular and biochemical characterization of a sand fly population from Sri Lanka: evidence for insecticide resistance due to altered esterases and insensitive acetyl cholinesterase. Bull Entomol Res. 2005;95:371-80.

13. Ilango K. A taxonomic reassessment of the Phlebotomus argentipes species complex (Diptera: Psychodidae: Phlebotominae). J Med Entomol. 2010;47:1-15.

14. Chamaillé L, Tran A, Meunier A, Bourdoiseau G, Ready P, Dedet J-P. Environmental risk mapping of canine leishmaniasis in France. Parasit Vectors. 2010;3:31.

15. Nieto P, Malone JB, Bavia ME. Ecological niche modeling for visceral leishmaniasis in the state of Bahia, Brazil, using genetic algorithm for ruleset prediction and growing degree day-water budget analysis. Geospat Health. 2006;1:115-26.

16. SSK N, Weligama DJ, Wijekoon CJ, Dissanayake M, Rajapaksha K. Cutaneous leishmaniasis in Sri Lanka. J Emerg Infect Dis. 2007:13:1068-70.

17. Department of Census and Statistics in collaboration with Ministry of Health, Sri Lanka Demographic and Health Survey 2006/2007. Colombo, Sri Lanka; 2007.

18. Food and Agriculture Organization. 2010. Global Forest Resources Assessment Country Report: Sri Lanka. Accessed 07 June 2011.

19. Department of Meteorology. Climate of Sri Lanka. 2016. http://www.meteo. gov.lk/index.php?option=com_content\&view=article\&id=94\&ltemid= 310\&lang=en. Accessed 26 June 2016

20. Sandanayaka R, Kahawita I, Gamage A, Siribaddana S, Agampodi S. Emergence of cutaneous leishmaniasis in Polonnaruwa, Sri Lanka 20082011. Tropical Med Int Health. 2014;19:140-5.

21. Singh SP, Hasker E, Picado A, Gidwani K, Malaviya P, Singh RP, et al. Risk factors for visceral leishmaniasis in India: further evidence on the role of domestic animals. Tropical Med Int Health. 2010;15:29-35.

22. Bern C, Hightower AW, Chowdhury R, Ali M, Amann J, Wagatsuma Y, et al. Risk factors for kala-azar in Bangladesh. Emerg Infect Dis. 2005;11:655-62.

23. Belen A, Alten B. Variation in life table characteristics among populations of Phlebotomus (Phlebotomus) papatasi at different altitude. J Vector Ecol. 2006;31:35-44.

24. Bhunia GS, Kesari S, Jeyaram A, Kumar V, Das P. Influence of topography on the endemicity of kala-azar: a study based on remote sensing and geographical information system. Geo Health. 2010;4:155-65.

25. Ranasinghe $S$, Wickremasinghe R, Munasinghe A, Hulangamuwa S, Sivanantharajah S, Seneviratne K, et al. Cross-sectional study to assess risk factors for leishmaniasis in an endemic region in Sri Lanka. Am J Trop Med Hyg. 2013;89:742-9.

26. Kesari S, Bhunia GS, Kumar V, Jeyaram A, Ranjan A, Das P. Study of houselevel risk factors associated in the transmission of Indian kala-azar. Parasit Vectors. 2010;3:94.

27. Ranawaka RR, Weerakoon HS, Opathella N, Subasinha C. Leishmaniasis in North Central Province, Sri Lanka - epidemiology and therapeutic response. Sri Lanka J Dermatol. 2010;14:4-8

28. GLS G, JAMB S, WMDR I, Wickramasinghe S, MDMLDK Y. Clinicoepidemiological patterns of cutaneous leishmaniasis patients attending to Anuradhapura Teaching Hospital, Sri Lanka. Korean J Parasitol. 2017;55:1-7.
29. Semage SN, KPN P, Agampodi SB. Cutaneous leishmaniasis in Mullaitivu, Sri Lanka: a missing endemic district in the leishmaniasis surveillance system. Int J Infect Dis. 2014;25:53-5.

30. Rajapaksa US, Ihalamulla RL, Udagedera C, Karunaweera ND. Cutaneous leishmaniasis in southern Sri Lanka. Trans R Soc Trop Med Hyg. 2007;101:799-803.

31. Premachandra WTS, Senarath DPC, de Silva MPKSK, Peiris BSAL. Study on phlebotomine sandflies (Diptera: Phlebotomidae) in Dickwella, southern SriLanka, an endemic focus for cutaneous leishmaniasis. Int J Trop Insect Sci. 2012:32:32-8.

32. Toumi A, Chlif S, Bettaieb J, Alaya NB, Boukthir A, Ahmadi ZE, et al. Temporal dynamics and impact of climate factors on the incidence of zoonotic cutaneous leishmaniasis in central Tunisia. PLoS Negl Trop Dis. 2012:5:e1633.

33. Abdel-Dayem MS, Annajar BB, Hanafi HA, Obenauer PJ. The potential distribution of Phlebotomus papatasi (Diptera: Psychodidae) in Libya based on ecological niche model. J Med Entomol. 2012;3:739-45.

34. Adegboye OA, Adegboye M. Spatially correlated time series and ecological niche analysis of cutaneous leishmaniasis in Afghanistan. Int J Environ Res Public Health. 2017;14:309.

35. Gage KL, Burkot TR, Eisen RJ, Hayes EB. Climate and vector-borne diseases. Am J Prev Med. 2008;35:436-50.

36. Ready PD. Leishmaniasis emergence in Europe. Euro Surveill. 2010;15:19505.

37. Abdullah AY, Dewan A, Shogib Rl, Rahman M, Hossain F. Environmental factors associated with the distribution of visceral leishmaniasis in endemic areas of Bangladesh: modeling the ecological niche. Trop Med Health. 2017;45:13.

38. Ranganathan S, Swaminathan S. Sandfly species diversity in association with human activities in the Kani tribe settlements of the Western Ghats, Thiruvananthapuram, Kerala, India. Mem Inst Oswaldo Cruz, Rio de Janeiro. 2015;110:174-80.

39. RMUK R, Chandrawansa PH, Rathnayake TL. Cutaneous leishmaniasis in southern Sri Lanka. In: Fourth World Congress of Leishmanaisis, India; Abstract book; 2009. p. 108.

40. Abedi-Astaneh F, Akhavan AA, Shirzadi MR, Rassi Y, Yaghoobi-Ershadi MR, Hanafi-Bojd AA, et al. Species diversity of sand flies and ecological niche model of Phlebotomus papatasi in central Iran. Acta Trop. 2015;149:246-53.

41. Hijmans RJ, Cameron SE, Parra JL, Jones PG, Jarvis A. Very highresolution interpolated climate surfaces for global land areas. Int J Climatol. 2005;25:1965-78.

42. Neerinckx SB, Peterson AT, Gulinck H, Deckers J, Leirs H. Geographic distribution and ecological niche of plague in sub-Saharan Africa. Int J Health Geogr. 2008;7:54.

43. Dhiman RC, Pahwa S, Dhillon G, Dash AP. Climate change and threat of vectorborne diseases in India: are we prepared? Parasitol Res. 2010;106:763-73.

44. Simsek FM, Alten B, Caglar SS, Ozbel Y, Aytekin AM, Kaynas S, et al. Distribution and altitudinal structuring of phlebotomine sand flies (Diptera: Psychodidae) in southern Anatolia, Turkey: their relation to human cutaneous leishmaniasis. J Vector Ecol. 2007:32:269-79.

45. Vivero RJ, Gutierrez CT, Bejarano EE, Peña HC, Estrada LG, Florez F, et al. Study on natural breeding sites of sand flies (Diptera: Phlebotominae) in areas of Leishmania transmission in Colombia. Parasit Vectors. 2015;8:116.

46. Yared S, Deribe K, Gebreselassie A, Lemma W, Akililu E, Kirstein OD, et al. Risk factors of visceral leishmaniasis: a case control study in north-western Ethiopia. Parasit Vectors. 2014;7:470

47. Emch M. Relationships between flood control, kala-azar, and diarrheal disease in Bangladesh. Environ Plan A. 2000;32:1051-63.

48. Mukhopadhyay AK, Rahaman SJ, Chakravarty AK. Effect of flood on immature stages of sandflies in a flood prone Kala-azar endemic village of North Bihar, India. Geneva: World Health Organization; 1990. 